Transpn Res. Vol. 2, pp. 329-338. Pergamon Press 1968. Printed in Great Britain

\title{
THE EFFECTS OF MIGRATION AND PERSONAL EFFECTIVENESS ON LONG-DISTANCE TRAVEL
}

\author{
JOHN B. LANSING \\ The University of Michigan, Ann Arbor, Michigan
}

(Received 24 August 1967; in revised form 29 January 1968)

\section{INTRODUCTION}

THE PROBLEM to which the research reported here is addressed is analysis of the demand for long-distance travel. Trips to places 100 miles away or more are considered. The analysis is based on a survey of a cross-section of the population of the United States conducted by the Survey Research Center of the University of Michigan in 1962. The novel element in this paper is the inclusion among the predictors of the volume of travel by individuals of measures of their prior geographic mobility and their personalities. Estimates will be presented of the relation between the geographic mobility of people and their subsequent frequency of travel, and of the relation between their sense of personal effectiveness and their frequency of travel.

It is not possible using a single cross-section survey to develop a complete model of all the variables which are related to the freqeuncy with which people travel. The method is poorly adapted to the estimation of the effects of some variables, such as changes over time in the price of transportation. The method is useful for isolating characteristics of individuals associated with differences in how many trips they take.

Apart from simple intellectual curiosity there are two basic reasons for interest in analysis of the demand for travel: forecasting and marketing. Most studies of forecasting rely upon projections into the future of the effects of the changing income distribution of the population and its changing demographic characteristics. The research presented here has some relevance to forecasting, especially to forecasting the volume of travel on particular routes, since it investigates the connections between migration and subsequent travel. The results are perhaps more directly concerned with problems of marketing, that is, problems of adapting the nature of the services supplied to the requirements of potential travellers. For the design and operation of transportation systems it is important to understand as thoroughly as possible who travels and why, as well as who does not travel, and the reasons why.

\section{HYPOTHESES}

In social research the process of analysis is sometimes a search for ideas that fit the data rather than the testing of hypotheses formulated in advance. In this project, however, the investigator approached the data with fairly definite expectations.

In previous work a taxonomy had been proposed of motives for travel and barriers to travel. Conventionally motives for travel are divided into business and non-business purposes. Three principal classes of reasons for non-business travel have been distinguished: desire for social prestige, desire for personal gratifications, and desire to visit friends and relatives. It is this last type of motivation which is related to migration. Since people often state that they travel to visit friends or relatives, it was expected when this analysis 
was undertaken that people who have migrated would be more likely to have friends or relatives at a distance than those who have not, and, since they have this extra reason to travel, would take more trips than those who have not migrated.

Five barriers to travel have been distinguished: expense, lack of time, old age and poor health, presence of children too young to travel, and lack of motivation to travel, especially lack of motivation to travel on the part of the spouse of someone who himself would like to take more trips. See Lansing and Blood (1964).

It was expected when the analysis was undertaken that people who score high in sense of personal effectiveness would travel more than those who score low. These people, as will be discussed below, may be better able to overcome the psychological difficulties associated with travel. Implicit in this expectation was the proposition that the psychological difficuities of travel constitute a sixth barrier to travel.

Finally, it was expected that achievement-security orientation would be related to travel. It was anticipated that achievement orientation would be a proxy for concern with status, which is one of the reasons for travel which is generally believed to have some importance. Hence, achievement-oriented people should travel more.

\section{METHOD}

The survey which is the source of the data to be presented here was undertaken primarily as a study of the geographic mobility of labor. A total of 1317 interviews were taken in August and September 1962 selected to represent all families in the United States who live in private dwelling units. The sample was selected using the method of area probability sampling. The first stage in the procedure was the selection of counties or county groups (primary sampling units). A total of sixty-six primary sampling units were selected, including the twelve largest metropolitan areas and fifty-four other counties or county groups. Within each of the sixty-six areas a probability sample of places was selected. These places might be cities, towns or rural areas. Within the sample of places a probability selection of dwellings was made. A dwelling might be a single family house or an apartment. Within the dwelling selected both the family of the head of the household and any other family living in the unit were designated for inclusion in the sample. A family might be one individual living alone, or two or more related individuals. When a family was selected for interview, the head of the family or the wife of the head was designated as the respondent on a random basis.

Since the study was designed for the purpose of investigating the geographic mobility of labor, only one question was asked about the frequency of travel of the people interviewed. It is the replies to this question which provide the dependent variable in this analysis. The exact wording of the question is as follows:

We're interested in how much people have travelled. In the last five years how often have you yourself taken trips to places 100 miles or more away?

[ ] Never [ ] Once or twice [ ] 3-5 times
[ ] 6-9 times [ ] 10 or more times

People's replies should not be interpreted as providing exact counts of numbers of trips. The answers, rather, have been used to classify people on an ordinal scale according to their frequency of travel, with scores ranging from 0 for those who say they never have taken a trip to 4 for those who have taken trips ten or more times. Previous work has shown that for purposes of maximizing the power of socio-economic variables to predict reported frequency of travel such a scale is to be preferred to a scale which assigns to each category a value based on its mid-point or the mean. See Lansing and Blood (1964). 
The method of statistical analysis used is multiple regression. The variables are defined in the Appendix and the original calculations are summarized in Tables A1 and A2. The only feature of these calculations in any way unusual is the use of dummy variables to handle three of the conceptual variables, age, education and achievement-security orientation. For a detailed discussion of this technique of treating multiple regressions see Melichar (1965). It is convenient to interpret results of dummy variable regressions of this type when they are expressed in the form of deviations from the grand mean. Accordingly, Table 1 shows the results from Table A1 transformed into adjusted deviations from the grand mean.

The results for family income, education of the head of the family, age of the head and automobile ownership are approximately as expected and require little discussion. All of these variables proved reliable statistically, and all have coefficients close to those found in earlier work. Income was constrained to have a linear effect. High-income people, of course, travel more. Age was not so constrained. It shows a decline in frequency of travel with advancing age, but the decline is not regular. There is a tendency for those between the ages of 35-44 to travel more than those between 25-34. Since young children are an obstacle to travel, a low frequency of travel for families with head aged about 30 is reasonable. College graduates travel much more than those who have lesser levels of education. Automobile ownership is positively associated with frequency of travel. These variables were introduced primarily to make it possible to look at the incremental effects of the new predictors.

In the regressions four variables were included which are related to geographic mobility. They are the following: location of close friends, location of close relatives, whether the head of the family is living at his birthplace and whether the wife is living at her birthplace. (The exact questions and the scales used are shown as before in the Appendix.)

The five items which make up the scale of personal effectiveness are shown in the Appendix. None of the items refers on its face to travel or vacations or anything of the kind. The scale was developed in a different context by investigators interested in quite different forms of behavior, such as voting in elections. See Campbell et al. (1960). Scores on this scale are correlated both with income and education, but in the present calculations both education and income are taken into account.

The method of scoring achievement-security orientation is shown in the Appendix. Respondents were placed in three groups: security-oriented, achievement-oriented, and neither security nor achievement orientation.

\section{RESULTS RELATED TO MIGRATION}

The greater the proportion of people's half-dozen closest relatives who live at a distance the more often people travel. As shown in Table 1, the difference in predicted score on frequency of travel between those all of whose closest relatives live nearby and those none of whose closest relatives live nearby is 0.45 . Location of friends has a similar but slightly smaller effect. The difference in predicted scores between the extremes on this scale is $0 \cdot 35$. There are indications that if the head is living at his birthplace the family tends to travel less than if he lived elsewhere, and the same is true if the wife is living at her birthplace even allowing for the effects of location of friends and relatives. The coefficients for living at a distance from place of birth are not large, however, and are not reliably different from zero, the other variables just mentioned being taken into account. These results require careful consideration.

The logical relationship which we should expect to find is that people travel in order to visit close friends and relatives from whom they are separated because of migration. It is the separation which is the proximate cause of travel. 
TABle 1. Frequency of TRAVEl in the five years before interview: AdJusted DIFFERENCES FROM THE MEAN

\begin{tabular}{lc}
\hline Explanatory variable & All individuals \\
\hline Grand mean & $2 \cdot 18$ \\
Family income & \\
Under $\$ 1000$ & $-0 \cdot 45$ \\
$\$ 1000-1999$ & $-0 \cdot 34$ \\
$\$ 2000-2999$ & $-0 \cdot 27$ \\
$\$ 3000-3999$ & $-0 \cdot 20$ \\
$\$ 4000-4999$ & $-0 \cdot 13$ \\
$\$ 5000-5999$ & $-0 \cdot 05$ \\
$\$ 6000-7499$ & $+0 \cdot 02$ \\
$\$ 7500-9999$ & $+0 \cdot 16$ \\
$\$ 10,000$ or over & $+0 \cdot 63$ \\
Age of head & \\
18-24 & $+0 \cdot 26$ \\
25-34 & $+0 \cdot 09$ \\
35-44 & $+0 \cdot 17$ \\
45 or more & $-0 \cdot 09$ \\
Education & \\
Less than 12 years & $-0 \cdot 12$ \\
Finished high school & $+0 \cdot 05$ \\
College & $+0 \cdot 34$ \\
Car ownership & \\
Own a car & $+0 \cdot 10$ \\
Own no car & $-0 \cdot 37$ \\
Location of closest friends & \\
All live nearby & $-0 \cdot 09$ \\
Most live nearby & $+0 \cdot 03$ \\
Only a few live nearby & $+0 \cdot 14$ \\
None live nearby & $+0 \cdot 26$ \\
Location of closest relatives & \\
All live nearby & $-0 \cdot 49$ \\
Most live nearby & $-0 \cdot 34$ \\
Only a few live nearby & $-0 \cdot 19$ \\
None live nearby & $+0 \cdot 11$ \\
Place of birth & $+0 \cdot 27$ \\
Head at birthplace & $-0 \cdot 05$ \\
Head not at birthplace & $+0 \cdot 10$ \\
Wife at birthplace & $+0 \cdot 25$ \\
Wife not at birthplace & \\
Personality & $-0 \cdot 09$ \\
Security orientation & $+0 \cdot 05$ \\
Neither security nor achievement orientation & $-0 \cdot 08$ \\
Achievement orientation & $+0 \cdot 12$ \\
Number of effective responses & $+0 \cdot 03$ \\
None & \\
One & \\
Two & \\
Three & \\
Four & \\
Five & \\
\hline & \\
\hline & \\
\hline
\end{tabular}


The separation is ordinarily the result of migration, but the migrant may be the close friend or relative rather than the person studied. Hence, for any individual whether he is separated from his close friends or relatives is a better predictor of his travel than whether he himself has migrated. For example, when parents and adult children live in different cities both equally have a motive for travel regardless of who migrated.

Separation without migration by anybody is possible, but must be unusual. Keep in mind that the questionnaire refers to people's half-dozen closest relatives, not to all their relatives. People's closest relatives are almost always members of their biological families, that is, their parents (including the parents of the husband or the wife), siblings or children. Separation of the members of a biological family is possible only as a consequence of migration of its members within the lifetime of the individual concerned. It is possible for a person to make friends while away from home temporarily. But surely it is unusual for a person to say that all or most of his half-dozen closest friends are people whom he met while on temporary absence from home. On the other hand, people who have just moved to a new community usually report that their closest friends live in their former home. See Lansing and Mueller (1967).

TABle 2. MATRIX OF CORRELATION COEFFICIENTS $\left(r_{i j}\right)$ FOR VARIABLES RELATED TO GEOGRAPHIC MOBILITY

\begin{tabular}{lcccc}
\hline & $\begin{array}{c}\text { Head at } \\
\text { birthplace }\end{array}$ & $\begin{array}{c}\text { Wife at } \\
\text { birthplace }\end{array}$ & $\begin{array}{c}\text { Location of } \\
\text { relatives }\end{array}$ & $\begin{array}{c}\text { Location } \\
\text { of friends }\end{array}$ \\
\hline Wife at birthplace & 0.38 & & & \\
Location of relatives & -0.43 & -0.35 & & \\
Location of friends & -0.29 & -0.24 & 0.49 & 0.20 \\
Number of trips taken & -0.16 & -0.08 & 0.25 & 0 \\
\hline
\end{tabular}

With these considerations in mind we may examine the matrix of bivariate correlation cocfficients, which is shown as Table 2. The two variables which measure whether the head and wife have moved away from their respective places of birth do show substantial correlations with the scale on location of close relatives $(r=-0.43$ and -0.35 , respectively). Yet these two variables do not and cannot explain all the variability in location of relatives since migration by the relatives is not taken into account. Similar considerations apply to the explanation of location of friends, but the correlation coefficients are lower. Whether a person is living at his birthplace tells us more about whether he is likely to be separated from his family than about where the people he now regards as his close friends are living. The measures of lacation of relatives and location of friends are correlated with number of trips taken, and, as noted above, these effects persist in a multivariate context. We should not insist that both the variables measuring whether people live at their birthplaces and the measures of separation appear as statistically reliable predictors in the same calculation. Once location of friends and location of relatives have been taken into account, there seems to be little or no incremental effect of migration on travel. Yet migration has an important indirect effect on travel by creating the separation of people from close friends and relatives.

\section{RESULTS RELATED TO PERSONALITY VARIABLES}

It will be recalled that two personality variables were investigated, achievementsccurity orientation and sense of personal effectiveness.

Statistically, the evidence for the importance of achievement-security orientation is marginal. It was anticipated that achievement orientation might be a proxy for concern with status, which, it will be remembered, is one of the reasons proposed above for travel. 
In view of the modest size of the regression coefficients and their instability (see Table A1), all that can be said is that this hypothesis may be correct.

The evidence is much stronger for the importance of the sense of personal effectiveness. The regression coefficient is five times its standard error, which statistically puts its importance beyond reasonable doubt. The absolute difference between the extremes on the effectiveness scale is 0.76 in predicted score on the dependent variable. That difference is not as large as that between the extreme high and extreme low income groups, or 1.8, but it is larger than that between an income of under $\$ 1000$ and one of $\$ 7500-9999$, which is only $0 \cdot 61$. In other words, differences in effectiveness make alnost as much difference in frequency of travel as differences in income!

In the regression equations calculated for sub-groups of the population, shown in Table Al, the sense of personal effectiveness of the head turns out to have a much more powerful effect on his travel behavior than that of the wife has on hers. It may be that the effectiveness of the head of the family determines the travel behavior of the entire family.

The statistical evidence, then, is strong that personal effectiveness is related to frequency of travel even when the effects of income, age, education and auto ownership are taken into account.

\section{INTERPRETATION}

Migration emerges as one of the basic indirect causes of travel. Migration separates people from their families and friends; in particular, it separates parents from children. This separation creates a motive for visits, which may be made either by the children visiting the parents, or the reverse.

Trips resulting from this type of separation should be most frequent along the routes of migration streams. Thus, the study of streams of migration is the study of one part of the demand for travel. The main streams of internal migration in American history have been carefully documented in the literature on migration, which is reviewed in Shryock (1964). For example, there has been a substantial population interchange between the South and the North Central region, but there has been comparatively little interchange between the South and the Northeast. Such differences should be reflected in differences in the volume and character of travel between these areas.

It is common in transportation research to use some type of gravity model to predict flows between centers of population. These models assume that masses of people attract one another. Specific consideration of the nature of this attraction may offer hope of refinement and improvement of such models. For that part of the attraction between centers of population arising from migration, the present work suggests that it is not the number of people in the centres of population which is directly relevant, but the migration stream between them.

It would be interesting to follow up this research by investigating whether forecasts of the volume of travel between areas such as states or countries could be improved by the use of data on migration as well as data on population and distance. Such an analysis, however, must await the compilation of data on the total volume of travel between pairs of origins and destinations. The available data on migration are reasonably adequate, but not the data on travel.

From a marketing point of view one special feature of travel resulting from migration is that it seems likely not to involve a demand for accommodations at the destination. People who are taking a trip in order to visit relatives or friends are likely to be guests in the homes of the people they visit. 
Why should the sense of personal effectiveness be related to frequency of travel? The sense of personal effectiveness represents feelings of mastery over the self and the environment. See Campbell et al. (1960), and, for an earlier discussion, Douvan and Adelson (1958). The fact that a sense of mastery over the environment is important in travel implies that travel involves situations which present psychological difficulties. Travel to new places especially implies a venture into the unknown. People may wonder nervously how they will be able to find their way, obtain food and lodging, and avoid strangers who seek to exploit them or injure them. From the point of view of the travel industry, the implication is that it is important to make travel psychologically easier, and make people feel more secure about it. Their confidence should be increased.

Much that is done in marketing travel may be understood in this light. A classic device to make travel psychologically easier is the conducted tour. The operators of a tour in effect take on themselves many of people's worries, worries as to what the trip will cost, how to get to the right place at the right time and not miss the plane, and the like.

One of the most important facts about the air travel market is that people who once have taken an air trip are more likely to travel by air in the future than those who have not, even when income, age, education and so forth are taken into account. See Lansing and Blood (1964). The explanation may be that the initial experience reduces people's feeling of insecurity. What was once psychologically a formidable undertaking may become increasingly familiar until in time it is routine, or even dull.

The same principle may also be applied to the design of new transportation systems. Such systems are more likely to achieve ready acceptance if they are not seen as psychologically threatening or difficult to cope with by the potential travellers.

In sum, the finding that a general personality characteristic, sense of personal effectiveness, has a substantial effect on the total number of trips people take implies that there is a general tendency for travel to be inhibited by the type of apprehension which people who score high on this characteristic most easily overcome.

\section{REFERENCES}

Campbell A., Converse P. E., Miller W. and Stokes D. E. (1960). The American Voter. John Wiley, New York (1960).

Douvan E. and Adelson, J. (1958). The psychodynamics of social mobility in adolescent boys. J. abnor. soc. Psychol. 56, 31-44 (1958).

Lansing J. B. and Bloon D. (1964). The Changing Travel Market. Institute for Social Research, Ann Arbor.

Lansing J. B. and Mueller E. (1967). The Geographic Mobility of Labor. Institute for Social Research, Ann Arbor.

MeLICHAR E. (1965). Least squares analysis of economic survey data. 1965 Proceedings of the Business and Statistics Section. American Statistical Association.

Shryock H. S., JR. (1964). Streams of migration. Population Mobility within the United States, Chapter 8 , pp. 233-284. Community and Family Study Center, University of Chicago.

\section{APPENDIX \\ Detailed Description of Variables \\ (Questions Asked and Scoring Systems)}

\section{Number of trips in last five years}

We're interested in how much people have travelled. In the last five years how often have you yourself taken trips to places 100 miles or more away?

[ ] Never [ ] Once or twice [ ] 3-5 times [ ] 6-9 times [ ] 10 or more times

Note: Categories shown were scaled in order from 0 to 4 . 
Family income

Would you tell me how much income you and your family will be making during this calendar year, 1962 ?

[ ] Under $\$ 1000$ [ ] $\$ 4000-4999 \quad$ [ ] $\$ 10,000-14,999$

[ ] $\$ 1000-1999 \quad$ [ ] $\$ 5000-5999 \quad$ [ ] $\$ 15,000-19,999$

[ ] $\$ 2000-2999 \quad$ [ ] $\$ 6000-7499 \quad$ [ ] $\$ 20,000$ and over

[ ] \$3000-3999 [ ] \$7500-9999

Does that include the income of everyone in the family? (Check correct box above to include total family income.)

Note: Score is based on mid-point of bracket divided by $\$ 500$. All incomes of $\$ 10,000$ or above were scored as if they were $\$ 15,000$. Incomes under $\$ 1000$ scored as zero.

Age of head

Asked in years.

\section{Education of head}

How many grades of school did (you) finish? (If more than eight)-Have (you) had any other schooling? What other schooling have you had? (If attended college)-Do you have a college degree?

Car ownership

Do you or anyone else in the family own an automobile?

\section{Location of friends}

Thinking of your (and your spouse's) close friends, do they all live in ... (mention name of this area), most live here, only a few live here, or none live here?

[ ] All live here [ ] Only a few live here

[ ] Most live here [ ] None live here

Note: Categories shown were scaled from 0 (all live here) to 3 (none live here).

\section{Location of relatives}

Thinking of your (and your spouse's) half-dozen or so closest relatives, do they all live here in ... (mention name of this area), most live here, only a few live here, or none live here?

[ 1 All live here [ ] Only a few live here

[ ] Most live here [ ] None live here

Note: Scored in the same manner as location of friends. 


\section{Place of birth}

Where was (head) born?

Where was (wife) born?

\section{Number of effective responses}

Have you usually felt pretty sure your life would work out the way you want it to, or have there been more times when you haven't been very surc about it?

\section{[ ] Pretty sure [ ] Haven't been very sure}

Are you the kind of person that plans his (her) life ahead all the time, or do you live more from day to day?

\section{[ ] Plans ahead [ ] Lives from day to day}

When you make plans ahead, do you usually get to carry out things the way you expected, or do things usually come up to make you change your plans?

\section{[ ] Things work out as expected [ ] Have to change plans}

Some people feel that other people push them around a good bit. Others feel that they run their lives pretty much the way they want to. How is it with you?

\section{[ ] Get pushed around [ ] Run own life}

Would you say you nearly always finish things once you start them, or do you sometimes have to give up before they are finished?

\section{[ ] Always finish [ ] Sometimes give up}

Note: Score is number of above questions to which the effective response was given.

\section{Achievement-security orientation}

Would you please look at this card and tell me which thing on this list about a job (occupation) you would most prefer (would want most for your husband); which comes next, which third and so forth?

An occupation in which:

Rank from 1 (most preferred) to 6 (least preferred)
A. Income is steady . .
B. Income is high ...
C. There's no danger of being fired or unemploycd
D. Working hours are short, lots of free time
E. Chances for advancement are good ..
F. The work is important, gives a feeling of accomplishment ..

Note: Those who ranked both $\mathrm{A}$ and $\mathrm{C}$ as 1,2 or 3 were classified as security-oriented. Those who ranked both $\mathrm{E}$ and $\mathrm{F}$ as 1,2 or 3 were classified as achievement-oriented. All other combinations were placed in the intermediate category. 
Table A1. Summary of regressions as CALCUlated

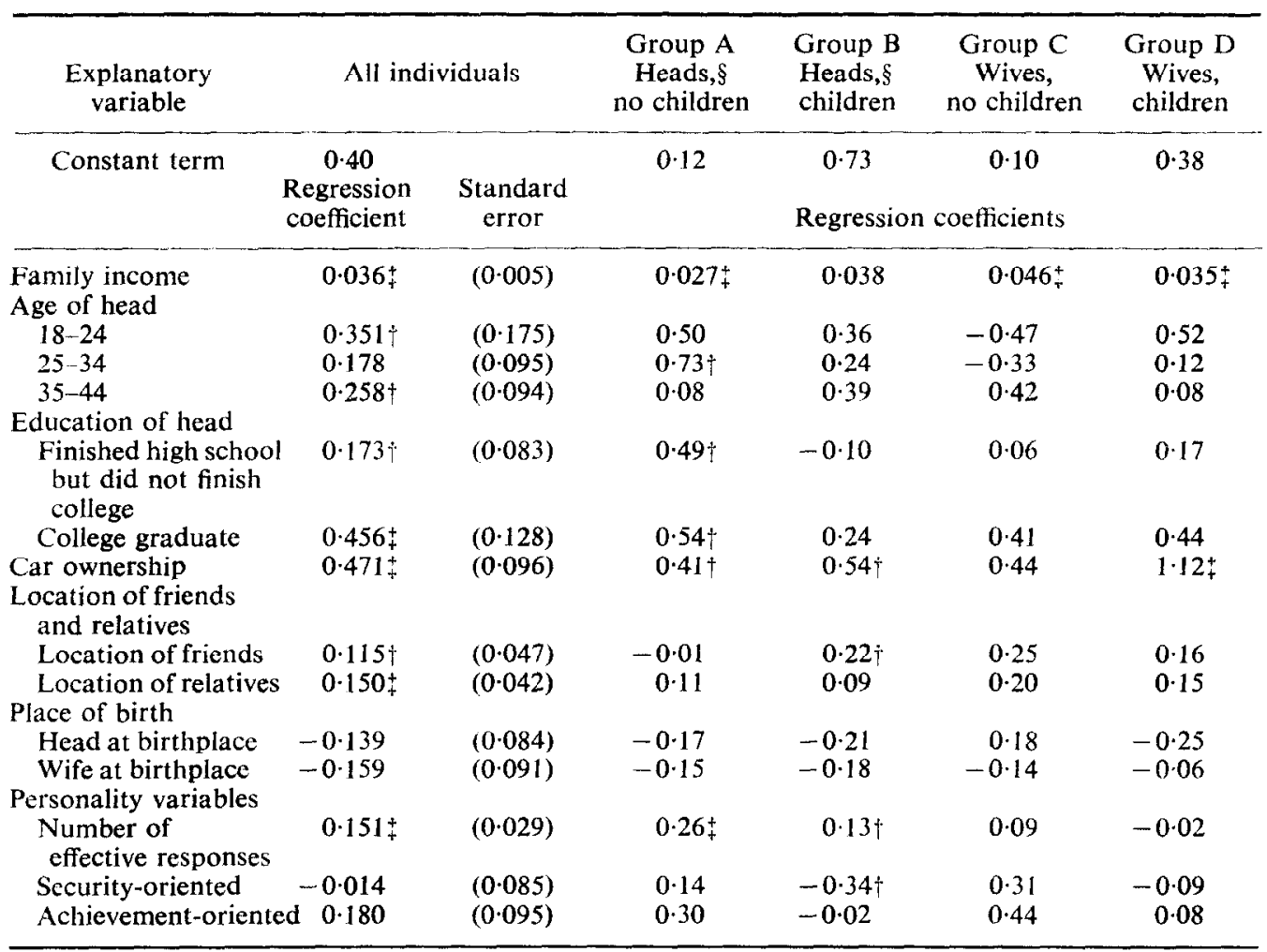

+ Coefficient at least twice its standard error but not three times its standard error.

¥ Coefficient three times its standard error or more.

$\$$ The head of a family is the husband if the family comprises a married couple. If there is only one adult in a family, for example, a widow, that individual is the head. Families with no children are those with no children under 18 living at home.

Note: Standard errors of regression coefficients shown were computed as if the survey had been a simple random sample. Conservative practice is to assume that the errors are understated by about 6 per cent because the actual sample is clustered. Errors shown for individual dummy variables test the reliability of the difference between the individual category and zero. For example, the coefficient for age 18-24 is 0.351 and its error is 0.175 . This coefficient, thus, is not estimated with precision. Yet, in view of the positive coefficients also found for the age groups $25-34$ and $35-44$, respectively, there is a high probability that age of head as a principle of classification is important, and that those aged over 45 travel less than those aged $18-44$.

TABLE A2. StATISTICS CHARACTERIZING REgRESSIONS

\begin{tabular}{|c|c|c|c|c|c|}
\hline & $\begin{array}{c}\text { All } \\
\text { individuals }\end{array}$ & $\begin{array}{c}\text { Group A } \\
\text { Heads, } \\
\text { no children }\end{array}$ & $\begin{array}{l}\text { Group B } \\
\text { Heads, } \\
\text { children }\end{array}$ & $\begin{array}{c}\text { Group C } \\
\text { Wives, } \\
\text { no children }\end{array}$ & $\begin{array}{l}\text { Group D } \\
\text { Wives, } \\
\text { children }\end{array}$ \\
\hline Multiple correlation coefficient & 0.52 & 0.57 & 0.53 & 0.54 & 0.49 \\
\hline Fraction of variance explained & 0.27 & 0.33 & 0.28 & $0 \cdot 30$ & $0 \cdot 24$ \\
\hline Residual degrees of freedom & 1302 & 419 & 348 & 193 & 289 \\
\hline Standard error of estimate & $1 \cdot 26$ & $1 \cdot 25$ & $1 \cdot 25$ & $1 \cdot 27$ & $1 \cdot 28$ \\
\hline Mean of dependent variable & $2 \cdot 18$ & $1 \cdot 94$ & $2 \cdot 39$ & $2 \cdot 23$ & $2 \cdot 25$ \\
\hline
\end{tabular}

